\title{
Fallopian Tube Adenosarcoma
}

National Cancer Institute

\section{Source}

National Cancer Institute. Fallopian Tube Adenosarcoma. NCI Thesaurus. Code C40125.

An extremely rare malignant neoplasm that arises from the fallopian tube and is

characterized by the presence of a benign epithelial component and a sarcomatous component. 